\title{
Compensation Contract Impact on Credit Rating Agencies' Decision toward Disclosing Accurate Credit Ratings
}

\author{
Kittiphod Charoontham \\ Khon Kaen University International College, Khon Kaen University, Thailand
}

\begin{abstract}
This study examines whether an upfront fee or an incentive pay scheme can more effectively discourage issuer-paid rating agencies (CRAs) from issuing inflated ratings. Under the incentive pay scheme, the CRA collects a fixed fee to cover her information production cost and gains rewards if issued ratings correctly reflect outcomes of rated portfolios. In the setting of consideration, an investor invests solely in a high-rated portfolio; the CRA can decide on the disclosure rule and effort exertion level in the information production process. Findings reveal that the incentive pay scheme provides better incentive for the CRA to adopt the full disclosure regime than the upfront fee scheme does. Conditional on the full disclosure regime being adopted by the CRA, the incentive pay scheme can induce the CRA to exert a higher level of effort in the information production process.
\end{abstract}

Key word: Incentive pay scheme, upfront fee scheme, rating quality, rating inflation regime, full disclosure regime, credit rating agencies

JEL Codes: G24, G28, and L14

\section{Introduction}

Credit ratings containing credit risk of underlying assets have been employed to mitigate asymmetric information between investors and issuers. Although credit ratings should be perceived as the third party's opinion toward creditworthiness of issuers or debt issues (Katz, Munoz, \& Stephanou, 2009), they are practically viewed by market participants (e.g., investors, issuers, creditors, and policymakers) as a guideline for investment decision. Banks use ratings to make decisions on lending money to firms and borrowing rates have negative relationship with credit ratings (Micu, Remolona, \& Wooldridge, 2004). Overall, ratings have been one of significant determinants for financial institutions when making investment and lending decisions (IOSCO, 2008). Accordingly, credit rating agencies (CRAs) have played an essential role in overcoming asymmetric information between issuing firms and market participant (e.g., financial institutions, fund managers, investors, etc.). Therefore, CRAs help enhancing market efficiency and preventing financial instability by producing informative ratings.

Existing literatures show that credit ratings have failed to foresee risk embedded in underlying financial assets and inflated ratings are particularly found in markets of structured finance products (Bonsall Iv, 2014). According to massive defaults of highly rated securities, CRAs are considered an important contributor to Hamburger crisis and have undergone intensive scrutiny. Subsequently, CRAs announce a series of negative watch listing and downgrades sovereign debts causing ongoing Eurozone crisis in 2010 (Afonso, Furceri, \& Gomes, 2012). Policymakers, financial regulators, and researchers have paid attention to how rating quality can be improved. 
Studies pinpoint that the issuer-paid model of CRAs provides opportunities for issuers to shop for ratings (Sangiorgi, Sokobin, \& Spatt, 2009), and conflict of interest inherent with the model motivates CRAs to inflate ratings to capture fee. In addition, the current payment system (e.g., the upfront fee scheme, and rating contingent fee scheme) can also incentivize CRAs to occasionally give out inflated ratings. Under the rating contingent fee scheme, CRAs are motivated to inflate ratings since they are compensated only if securities being rated receive favorable ratings (Weber \& Darbellay, 2008). Under the upfront fee scheme, CRAs charge an upfront fee in exchange for rating services and they are not financially affected by outcome of rated securities. Thus, CRAs occasionally have incentives to inflate ratings, especially in booming economy (Nwogugu, 2013). To discourage CRAs from inflating ratings, the CRAs should be compensated only if the announced ratings accurately reflect risk of securities or portfolios they rate (Partnoy, 2009).

Attempting to discourage CRAs from inflating ratings and improve rating quality, an incentive pay scheme which ties the outcome of rated securities to CRAs' performance is theoretically analysed. This payment scheme has not been analysed on the CRAs' incentive to strategically select rating policy and exert effort in information production process. In a model setting, the CRA can decide rating policy to be implemented and effort level put in information production process; the investor invest in high-rated securities only. To determine a better payment scheme, the CRA's conduct on selecting rating policy and exerting effort level in the information production process under the upfront fee scheme is compared with that under the incentive pay scheme. Findings reveal that the incentive pay scheme provides more incentive to the CRA to adopt the full disclosure regime than the upfront fee scheme. In addition, the incentive pay scheme motivates the CRA to exert higher effort level in the information production process than the upfront fee scheme.

\section{Literature Review}

Existing studies have recorded that both exogenous and endogenous factors have significant influence on CRAs' decision on inflating ratings. Exogenous factors that potentially motivate CRAs to inflate ratings are issuing firms' rating shopping behavior (Skreta \& Veldkamp, 2009), regulatory advantages gained from favorable ratings (Opp, Opp, \& Harris, 2013), and reducing barriers to entry of the CRA industry (Sangiorgi \& Spatt, 2015). Endogenous determinants that vitally deteriorate rating quality of CRAs are the intension to develop a long-term relationship with issuers (Mullard, 2012), inadequate rating models (Benmelech \& Dlugosz, 2009), and analysts' prejudices (Ashcraft, Goldsmith-Pinkham, Hull, \& Vickery, 2011). Existing studies reveal that issuing firms and CRAs are incentivized to provisionally advocate rating shopping, leading to low rating quality.

To mitigate CRAs' conduct of inflating ratings, several literatures investigate impact of different payment schemes on rating quality improvement. Ozerturk (2014) examined if the upfront fee contract or the rating contingent fee contract would more effectively induce CRAs to improve rating quality. The findings showed that the upfront fee scheme can better motivate CRAs to improve rating accuracy than the rating contingent fee scheme when rating policy is imposed by the CRAs after issuers purchase ratings. However, this study emphasizes on impact of the incentive pay scheme, where the CRAs' compensation is directly tied to their performance, on rating quality improvement. A mandatory co-investment scheme proposed by Bongaerts (2013) obliges CRAs to partially invest in projects or securities obtaining high ratings in hope for aligning CRAs' with investors' incentives. The co-investment scheme is closely related to the incentive pay scheme because CRAs are financially affected by the consequence of securities they rate. A commission contract introduced by Kashyap and Kovrijnykh (2016) binds CRAs' payment to their performance. They investigated impacts of different agents (investors, social planners, and issuing firms), who purchase ratings from CRAs, on rating quality. As a result, the lowest rating accuracy is expected when the issuing firms solicit ratings. Nevertheless, this study is different from the 
preceding literatures because this study incorporates the CRAs' conduct of strategically inflating ratings into the setting of consideration.

Pivotal differences between this study and extant literatures earlier mentioned are twofold. Firstly, CRA's conduct of inflating ratings is taken into account. Secondly, how rating quality is affected by CRA's strategic decision on adopting rating policy and exerting effort in the information production process under the upfront fee and the incentive pay scheme is illustrated.

\section{Model}

In a one-period model setting, a CRA and an investor are fully rational. The investor (he) has sufficient fund and invests only in a loan portfolio, receiving a high rating (an investment grade). A fraction of good loan portfolio $\gamma \in[0,1]$ and bad portfolio $1-\gamma$ are publicly known. A good loan portfolio $G$ generates positive payoff, $R>0$, while a bad one $B$ yields zero return, $R=0$.

The CRA has information production technology that can evaluate the portfolio quality giving out a signal, $s \in\{g, b\}$, where $g$ denotes a good portfolio and $b$ signifies a bad one. When the CRA does not put effort in the information production process, the probability that the observed signal $s$ is likely accurate is 0.5 . The CRA can enhance signal accuracy by putting effort $e \in[0,0.5]$ to improve rating quality to $0.5+e$. That is,

$$
\operatorname{Pr}\{s=g \mid G\}=\operatorname{Pr}\{s=b \mid B\}=0.5+e
$$

The CRA incurs the information production cost with effort level given by

$$
C(e)=\frac{\theta}{2} e^{2} \quad \text { and } \quad C(0)=0
$$

where $\theta>0$ is a scale parameter representing cost of hiring analysts and improving rating models to cope with increasing complexity of the portfolio complexity. In addition, it is unlikely possible for the CRA to observe the portfolio quality with certainty, $\lim _{e \rightarrow 0.5} C(e)=+\infty$. After observing the signal $s$, the CRA announces the rating of the portfolio, $r \in\{h, l\}$, where $h$ and $l$ represent a high and low rating respectively. The reported rating can reflect the observed signal (the full disclosure regime) or possibly be inflated (the rating inflation regime) depending on the CRA's profit maximization decision. The probability that the CRA reports a high rating when observing a bad signal is signified by $\sigma \in[0,1]$. That is,

$$
\begin{gathered}
\operatorname{Pr}\{r=h \mid s=b\}=1-\operatorname{Pr}\{r=l \mid s=b\}=\sigma \\
\operatorname{Pr}\{r=h \mid s=g\}=1
\end{gathered}
$$

The sequence of a rating production process is: (i) the CRA privately exerts effort in evaluating the portfolio quality and verifies a signal $s$, (ii) the CRA decides on a disclosure regime $\sigma$ (inflated rating probability), (iii) the CRA releases a rating $r$, and (iv) the investor invests in the loan portfolio when it obtains a high rating from the CRA.

\section{Credit Rating Agency Analysis}

When observing a signal of the loan portfolio, the CRA can strategically select whether to report ratings truthfully or inflate ratings in hope for maximizing her expected payoff. When the CRA observes a good signal, she absolutely assigns a high rating because it satisfies the investor's objective. In contrast, if the CRA observes a bad signal, she strategically decides on which rating to 
publicly disclose, signified by the inflated rating probability $\sigma$. When the CRA strategically engages in the rating inflation regime, the probability that the portfolio gets a high rating is:

$$
\pi_{h}(e, \sigma)=0.5(1+\sigma)+(2 \gamma-1)(1-\sigma) e
$$

The probability that a high-rated portfolio succeeds is given by

$$
\pi_{h s}(e, \sigma)=\frac{\gamma[0.5(1+\sigma)+e(1-\sigma)]}{0.5(1+\sigma)+(2 \gamma-1)(1-\sigma) \theta}
$$

The probability that a portfolio receives a low rating is given by

$$
\pi_{l}(e, \sigma)=[0.5+(1-2 \gamma) e](1-\sigma)
$$

The probability that a low-rated portfolio defaults is given by

$$
\pi_{l d}(e, \sigma)=\frac{(1-\gamma)(0.5+e)(1-\sigma)}{[0.5+(1-2 \gamma) \epsilon](1-\sigma)}
$$

The CRA weighs expected reputational cost against benefit from inflating ratings. The expected reputational cost is the discounted sum of future loss borne by the CRA when assigned ratings do not reflect the actual performance of portfolios due to diminished confidence of potential investors. Monetary loss, $\tau>0$, incurs when the high-rated portfolio turns out to default or the low-rated portfolio succeeds. The expected reputational cost that the CRA bares is given by

$$
\Psi(e, \sigma ; \tau)=[0.5-e+(0.5+e-\gamma) \sigma] \tau
$$

The CRA can strategically select the disclosure rule $\sigma$ and her effort level being exerted in an information production process $e$; knowing that the investor will invest in the portfolio only if it obtains a high rating. The CRA can select one of the three rating policies: (i) full disclosure $(\sigma=0)$, (ii) partial disclosure $(0<\sigma<1)$, or (iii) rating inflation $(\sigma=1)$ to maximize her expected payoff. To investigate the CRA's decision on adopting rating policy and improving rating quality under different payment schemes, we will examine the CRA's optimal rating policy and the implicit effort level she puts in the information production process.

\subsection{The Upfront Fee Scheme}

Under this scheme, the CRA charges an upfront fee, $f^{u}>0$, regardless of a good or bad rating is assigned to a portfolio in hope for maximizing her expected payoff. Therefore, the CRA's expected profit is given by

$$
\Pi^{u}\left(e, \sigma_{;} f^{u}\right)=\max _{\sigma_{i} \varepsilon}\left[f^{u}-C(e)-\Psi(e, \sigma ; \tau)\right]
$$

Proposition 1: The optimal rating policy the CRA adopts is described by a threshold of reputational cost $\bar{\tau}^{u}:=\theta(2 \gamma-1)$ as follows:

(i)For $\tau \geq \bar{\tau}^{u}$, it is optimal for the CRA to exert effort in the information production process, $e_{u}^{*}=\frac{\tau}{\theta}$, and adopt the full disclosure regime, $\sigma^{*}=0$.

(ii) For $\tau<\bar{\tau}^{u}$, it is optimal for the CRA to exert no effort in the information production process, $e_{u}^{*}=0$, and adopt the rating inflation, $\sigma^{*}=1$.

It is straightforward to see that the CRA fully discloses rating information, $\sigma^{*}=0$, when the reputational loss from misreporting is higher than the threshold $\bar{\tau}^{u}$. The CRA 
also optimally puts effort in the information production process, $e_{u}^{*}=\frac{\pi}{\theta}$. In this case, the CRA realizes that a major fraction of the portfolio consists of bad loans, highly exposed to default risk. To hedge against the expected reputational loss, the CRA needs to exert sufficiently high effort to produce informative ratings in order to survive in the market. If the expected reputational loss is fundamentally low $\tau<\bar{\tau}^{u}$, the CRA implements the rating inflation regime, $\sigma^{*}=1$, and tends not to put effort in the information production process, $e_{u}^{*}=0$. In order to minimize information production cost in this case, the CRA needs not to exert effort in the information production process since she is exposed to relatively low reputational loss or a significant portion of the portfolio composes of good loans, exposed to relatively low default risk.

\subsection{The Incentive Pay Scheme}

Under this scheme, the CRA is compensated with the incentive fee, $f^{i}>0$, only if an assigned rating is consistent with outcome of a loan portfolio to maximize her payoff. In other words, the CRA is rewarded if the high-rated portfolio succeeds or the low-rated portfolio defaults. Therefore, the CRA's expected payoff is given by

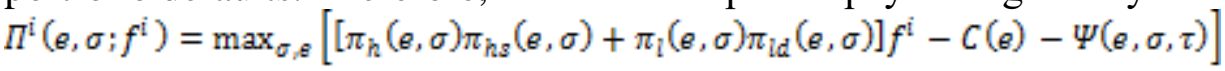

Proposition 2: The optimal rating policy the CRA adopts is implicitly characterized by a threshold of reputational cost $\bar{\tau}^{i}:=(2 \gamma-1) \theta-f^{i}$ as follows:

(i) For $\tau \geq \bar{\tau}^{i}$, it is optimal for the CRA to exert effort, $e_{i}^{*}=\frac{f^{\bar{i}}+\tau}{\theta}$, to observe a signal and adopt the full disclosure regime, $\sigma^{*}=0$.

(ii) For $\tau<\bar{\tau}^{i}$, it is optimal for the CRA to exert no effort, $e_{i}^{*}=0$, in observing a signal and implement the rating inflation, $\sigma^{*}=1$.

It is straightforward to see that the CRA makes a decision to strategically choose rating policy based on the reputational loss she possibly bares. If the expected reputational loss exceeds the threshold $\bar{\tau}^{i}$, the CRA opts for the full disclosure regime, $\sigma^{*}=0$, and optimally exerts effort in the information production process, $e_{i}^{*}=\frac{f^{i}+\tau}{\theta}$, to maximize her expected payoff. After observing a signal in this case, the CRA notices that the portfolio contains a large portion of bad loans, highly exposed to default risk. In order to maximize a chance to obtain incentive fee and hedge against the expected reputational loss, the CRA needs to exert sufficiently high effort to produce informative ratings and report ratings truthfully. If the expected reputational loss is adequately lower than the threshold, $\tau<\bar{\tau}^{i}$, the CRA tends not to exert effort in the information production process, $e_{i}^{*}=0$, and adopts the rating inflation regime, $\sigma^{*}=1$. In this case, the CRA is exposed to exceptionally low reputational loss or a major portion of the portfolio composes of good loans. The CRA inflates ratings and needs not to exert effort in the information production process. In addition, the CRA tends to diversify risk by increasing a number of her customers to gain more fees.

\subsection{Compensation scheme effect on rating quality improvement}


It is earlier illustrated that it is optimal for the CRA to strategically implement the full disclosure or the rating inflation regime based on the reputational cost threshold regardless of the compensation schemes being offered. To determine which compensation scheme is more efficient in terms of discouraging the CRA from issuing inflated ratings, the CRA's reputational cost threshold and optimal effort levels under the upfront fee contract are compared with that under the incentive pay contract.

Proposition 3: The incentive pay scheme provides higher incentive for the CRA to improve rating quality characterized by

(i) The CRA's reputational cost threshold under the upfront fee contract is higher than that under the incentive pay fee contract, $\bar{\tau}^{u}>\bar{\tau}^{\bar{i}}$.

(ii) The CRA's effort level in the information production process under the incentive pay scheme is higher than that under the upfront fee contract, $e_{i}^{*}>e_{u}^{*}$.

From Proposition 3, the CRA's reputational cost threshold under the upfront fee $\bar{\tau}^{u}:=(2 \gamma-1) \theta$ is higher than that under the incentive fee $\bar{\tau}^{i}:=(2 \gamma-1) \theta-f^{i}$. Suppose that $\tau=(2 \gamma-1) \theta-f^{i}$. The CRA under the incentive pay scheme implements the full disclosure regime while the CRA under the upfront fee still adopts the rating inflation since $\tau<\bar{\tau}^{u}$. Therefore, the incentive pay fee can better encourage the CRA to adopt the full disclosure regime than the upfront fee so that the incentive pay scheme induces the CRA to issue more informative ratings to overcome asymmetric information between the issuing firms and investors than the upfront fee scheme. To maximize the expected payoff, the CRA under the incentive pay scheme needs to give out accurate ratings to capture the incentive fee and, in turn, avoid the expected reputational loss in this case. The incentive pay fee incentivizes the CRA to exert higher effort level than the upfront fee if the CRA under both payment schemes adopts the full disclosure regime, $e_{i}^{*}>e_{u}^{*}$. Conditional on the full disclosure regime being adopted, the CRA under the incentive pay fee puts higher effort level resulting in more accurate ratings because she can claim incentive fee when the issued ratings accurately reflect true quality of the portfolios. The CRA under the incentive pay fee can in turn minimize the expected reputational loss at the same time.

\section{Conclusion}

To alleviate rating inflation problems, this study focuses on which payment scheme between the upfront fee and the incentive pay fee can encourage the issuer-paid rating agency to improve rating quality. In the model setting, the CRA can strategically choose whether to truthfully report ratings or inflate ratings, and effort level being put in the information production process. The CRA's behavior of issuing inflated ratings is also considered. Finding reveals that the CRA's reputational cost threshold under the incentive pay scheme is lower than that under the upfront scheme, and the CRA's effort level in the information production process under the incentive pay scheme is higher than that under the upfront scheme conditional on the full disclosure regime being implemented by the CRA.

A critical finding of this study is that the proposed incentive pay contract can effectively encourage the CRA to truthfully report rating information and increase effort level in the information production process to improve rating quality. Although the incentive pay 
scheme may still result in inflated ratings when the CRA's expected reputational loss is sufficiently low or the rated portfolios are likely exposed to exceptionally low default risk. The insights from this study can guide regulators and policy developers in proposing the policy reform regarding compensation scheme of the CRA to increase rating accuracy, enhance market efficiency, and forestall financial instability ignited by uninformative ratings. For academic insights, this study illustrates the CRA's strategic decision on selecting rating policy and exerting effort level in the information production process. Future studies may consider other payment schemes which can induce CRAs to produce more accurate ratings.

\section{References}

1. Afonso, A., Furceri, D., \& Gomes, P. (2012). Sovereign credit ratings and financial markets linkages: Application to European data. Journal of International Money and Finance, 31(3), 606-638. doi: http://dx.doi.org/10.1016/j.jimonfin.2012.01.016

2. Ashcraft, A., Goldsmith-Pinkham, P., Hull, P., \& Vickery, J. (2011). Credit Ratings and Security Prices in the Subprime MBS Market. The American economic review, 101(3), 115-119.

3. Benmelech, E., \& Dlugosz, J. (2009). The alchemy of CDO credit ratings. Journal of Monetary Economics, 56(5), 617-634. doi: http://dx.doi.org/10.1016/j.jmoneco.2009.04.007

4. Bongaerts, D. (2013). Can alternative business models discipline credit rating agencies: Working paper.

5. Bonsall Iv, S. B. (2014). The impact of issuer-pay on corporate bond rating properties: Evidence from Moody's and S\&P's initial adoptions. Journal of Accounting and Economics, 57(2-3), 89-109. doi: http://dx.doi.org/10.1016/j.jacceco.2014.01.001

6. IOSCO. (2008). The Role of Credit Rating Agencies in Structured Finance Markets: Final Report. from Retrieved July 10th, 2014, from OICV-IOSCO (International Organization of Securities Commissions) http://www.iosco.org/library/pubdocs/pdf/IOSCOPD270.pdf

7. Kashyap, A. K., \& Kovrijnykh, N. (2016). Who Should Pay for Credit Ratings and How? Review of Financial Studies, 29(2), 420-456. doi: 10.1093/rfs/hhv127

8. Katz, J. G., Munoz, E. S., \& Stephanou, C. (2009). Credit rating agencies: No easy regulatory solutions. The World Bank Group, Financial and Private Sector Development Vice Presidency, Crisis Response Policy Brief, 8.

9. Micu, M., Remolona, E., \& Wooldridge, P. (2004). The price impact of rating announcements: evidence from the credit default swap market. BIS Quarterly Review, 2(June), 55-65.

10. Mullard, M. (2012). The Credit Rating Agencies and Their Contribution to the Financial Crisis. The Political Quarterly, 83(1), 77-95. doi: 10.1111/j.1467923X.2012.02268.x

11. Nwogugu, M. C. (2013). Problems Inherent in The Compensation and Business Models of Credit Rating Agencies. Available at SSRN 1761406.

12. Opp, C. C., Opp, M. M., \& Harris, M. (2013). Rating agencies in the face of regulation. Journal of Financial Economics, 108(1), 46-61. doi: http://dx.doi.org/10.1016/j.jfineco.2012.10.011 
13. Ozerturk, S. (2014). Upfront versus rating contingent fees: Implications for rating quality. Finance Research Letters, 11(2), 91-103. doi: 10.1016/j.frl.2013.11.003

14. Partnoy, F. (2009). Rethinking regulation of credit rating agencies: An institutional investor perspective. Council of Institutional Investors, April, 09-014.

15. Sangiorgi, F., Sokobin, J., \& Spatt, C. (2009). Credit-rating shopping, selection and the equilibrium structure of ratings: Working Paper, Stockholm School of Economics and Carnegie Mellon University.

16. Sangiorgi, F., \& Spatt, C. S. (2015). Opacity, credit rating shopping and bias. Credit Rating Shopping and Bias (April 29, 2015), working paper.

17. Skreta, V., \& Veldkamp, L. (2009). Ratings shopping and asset complexity: A theory of ratings inflation. Journal of Monetary Economics, 56(5), 678-695. doi: http://dx.doi.org/10.1016/j.jmoneco.2009.04.006

18. Weber, H. R., \& Darbellay, A. (2008). The regulatory use of credit ratings in bank capital requirement regulations. Journal of Banking Regulation, 10(1), 1-16. doi: $10.1057 /$ jbr.2008.22

\section{Acknowledgement}

This proceeding is granted by Khon Kaen University.

\section{Appendix}

\section{Proof of Proposition 1:}

We will show that the optimal rating policy for the CRA is either the full disclosure $(\sigma=0)$ or rating inflation $(\sigma=1)$. Substituting equation (8) into equation (9), the CRA's expected payoff under the upfront fee is given by

$$
\begin{aligned}
& \Pi^{u}\left(e, \sigma_{;} f^{u}\right)=f^{u}-\frac{\theta}{2} e^{2}-[0.5-e+(e+0.5-\gamma) \sigma] \tau \\
& \text { where } \\
& \qquad \frac{\partial \pi^{u}\left(e_{2} \sigma_{i} f^{u}\right)}{\partial \sigma}=-[e+0.5-\gamma] \tau
\end{aligned}
$$

Since the CRA's expected payoff function is linear in $\sigma$, the optimal regime for the CRA is either the full disclosure $\left(\sigma^{*}=0\right)$, or the rating inflation $\left(\sigma^{*}=1\right)$.

If $\sigma^{*}=0$, we have that $\Pi^{u}\left(e, \sigma^{*}=0 ; f^{u}\right)$ is concave in $e$ with a unique solution to the first-order condition given by $e_{u}^{*}=\frac{\pi}{\theta}$. Accordingly, the CRA's expected payoff is given by

$$
\Pi^{u}\left(e_{u}^{*}=\frac{\tau}{\theta}, \sigma^{*}=0 ; f^{u}\right)=f^{u}+\frac{\tau^{2}}{2 \theta}-0.5 \tau
$$

If $\sigma^{*}=1$, we have that $\Pi^{u}\left(e, \sigma^{*}=1 ; f^{u}\right)$ is independent of the CRA's effort level in information production process, $e_{u}^{*}=0$. Accordingly, the CRA's expected payoff is:

$$
\Pi^{u}\left(e_{u}^{*}=0, \sigma^{*}=1 ; f^{u}\right)=f^{u}-\tau+\gamma \tau
$$

Comparing $\Pi^{u}\left(e_{u}^{*}=\frac{\tau}{\theta}, \sigma^{*}=0 ; f^{u}\right)$ with $\Pi^{u}\left(e_{u}^{*}=0, \sigma^{*}=1 ; f^{u}\right)$, there exists the threshold of reputational cost $\bar{\tau}^{u}:=(2 \gamma-1) \theta$ that the optimal rating policy for the CRA 
is the full disclosure regime $\left(\sigma^{*}=0\right.$ ) if $\tau \geq \bar{\tau}^{u}$. The optimal rating policy for the CRA is the rating inflation regime $\left(\sigma^{*}=1\right)$ if $\tau<\bar{\tau}^{u}$, otherwise.

\section{Proof of Proposition 2:}

We will demonstrate that the optimal rating policy for the CRA is the full disclosure $(\sigma=0)$ or rating inflation $(\sigma=1)$. Substituting equations from (4) to (8) into equation (10), the CRA's expected payoff under the incentive pay scheme is:

$$
\Pi^{i}\left(e, \sigma ; f^{i}\right)=[\gamma \sigma+(0.5+e)(1-\sigma)] f^{i}-\frac{\theta}{2} e^{2}-[0.5-e+(e+0.5-\gamma) \sigma] \tau
$$

Where

$$
\frac{\partial \pi^{\tilde{i}}\left(\varepsilon_{1}, \sigma_{i} f^{\tilde{1}}\right)}{\partial \sigma}=[\gamma-(0.5+e)] f^{i}-[e+0.5-\gamma] \tau
$$

Since the CRA's expected payoff function is linear in $\sigma$, the optimal regime for the CRA is either the full disclosure $\left(\sigma^{*}=0\right)$, or rating inflation $\left(\sigma^{*}=1\right)$.

If $\sigma^{*}=0$, we have that $\Pi^{i}\left(e, \sigma^{*}=0 ; f^{i}\right)$ is concave in $e$ with a unique solution to the first-order condition given by $e_{i}^{*}=\frac{f^{i}+\tau}{\theta}$. Accordingly, the CRA's expected payoff is:

$\Pi^{i}\left(e_{i}^{*}=\frac{f^{i}+\tau}{\theta}, \sigma^{*}=0 ; f^{i}\right)=0.5\left(f^{i}-\tau\right)+\frac{\left(f^{i}+\tau\right)^{2}}{2 \theta}$

If $\sigma^{*}=1$, we have that $\Pi^{u}\left(e, \sigma^{*}=1 ; f^{i}\right)$ is independent of the CRA's effort in information production process, $e_{i}^{*}=0$. Accordingly, the CRA's expected payoff is:

$\Pi^{i}\left(e_{i}^{*}=0, \sigma^{*}=1 ; f^{i}\right)=\gamma f^{i}-\tau(1-\gamma)$

Comparing $\Pi^{i}\left(e_{i}^{*}=\frac{f^{i}+\tau}{\theta}, \sigma^{*}=0 ; f^{i}\right)$ with $\Pi^{i}\left(e_{i}^{*}=0, \sigma^{*}=1 ; f^{i}\right)$, there exists the threshold of reputational cost $\bar{\tau}^{i}:=(2 \gamma-1) \theta-f^{i}$ that the optimal rating policy for the CRA is the full disclosure regime $\left(\sigma^{*}=0\right)$ if $\tau \geq \bar{\tau}^{i}$. Otherwise, the optimal rating policy for the CRA is the rating inflation regime $\left(\sigma^{*}=1\right)$ if $\tau<\bar{\tau}^{i}$.

\section{Proof of Proposition 3:}

We will show that the incentive pay scheme is better than the upfront fee scheme in terms of encouraging the CRA to report ratings truthfully and put higher effort level in the information production process.

3.1 Comparing the reputational cost threshold under the upfront fee contract, $\bar{\tau}^{u}:=(2 \gamma-1) \theta$, with that under the incentive pay scheme, $\bar{\tau}^{i}:=(2 \gamma-1) \theta-f^{i}$. It is simple to see that $\bar{\tau}^{u}>\bar{\tau}^{i}$.

3.2 Comparing the CRA's optimal effort under the upfront fee scheme, $e_{u}^{*}=\frac{\pi}{\theta}$, with that under the incentive pay scheme, $e_{i}^{*}=\frac{f^{\tilde{i}}+\tau}{\theta}$. It is apparent that $e_{i}^{*}>e_{u}^{*}$. 